\title{
RECLUTA DE TROPAS Y BANDOLERISMO DURANTE EL REINADO DE CARLOS II: EL CASO DE LA COMPAÑÍA ILICITANA DEL CAPITÁN GASPAR IRLES (1677)
}

\author{
Antonio ESPINO LÓPEZ \\ Universitat Autònoma de Barcelona
}

\begin{abstract}
Resumen
Uno de los procedimientos más usuales a la hora de obtener tropas para engrosar los ejércitos hispánicos fuera de las fronteras peninsulares ibéricas fue el recurso al servicio de compañías de bandidos. Gracias a este método, además, se conseguía suprimir, aunque fuese temporalmente, las actividades de determinadas cuadrillas, casi todas ellas de actuación comarcal, a cambio de ofrecer el perdón a los cabecillas y su séquito. En este trabajo, además de trazar un recorrido comparativo con otras experiencias, analizamos concretamente el caso de la compañía del capitán G. Irles, de Elche, embarcado para Italia junto con sus hombres en 1677 .
\end{abstract}

Palabras clave: Bandidos, Ejército, Siglo XVII, Elche, Redención de Penas.

\section{Summary}

Recruiting troops and bandolerism during Charles II's reign. The case of captain Gaspar Irles (1677)'s company.

One of the most usual proceedings to obtain troops to join the spanish armies outside peninsular frontiers had been recruting companies of outlaws. Thanks to that, activities of sone outlaws acting in a determinate region could eventually have been supressed granting a pardon to their leaders and men. In this article, we trace a comparison among other experiences and we analyze the case of captain G. Irles' company, to the city of Elche, for he was imbarked to Italy with his men in 1677.

Key words: Outlaw, army, XVII th. century, redemption of penalties, city of Elche

Como es bien sabido, dentro del proceso de detracción de hombres, rentas y servicios que la Monarquía Hispánica sometió tanto a los reinos de la corona de Castilla como a los de la corona de Aragón durante la época de los Austrias, sin duda uno de 
los procedimientos más usuales a la hora de obtener tropas para engrosar los ejércitos hispánicos fuera de las fronteras peninsulares ibéricas fue el recurso al servicio de compañias de bandidos. Gracias a este método, además, se conseguía suprimir, aunque fuese temporalmente, las actividades de determinadas cuadrillas, casi todas ellas de actuación comarcal, a cambio de ofrecer el perdón a los cabecillas y su séquito. Aunque también hubiese otros posibles intereses.'

En el caso del reino de Valencia ${ }^{2}$-como en Cataluña ${ }^{3}$ o en Mallorca- la utilización de la recluta de bandidos fue especialmente notable en el transcurso del siglo XVII.

\section{LA EXPERIENCIA VALENCIANA}

En la Valencia del reinado de Carlos II (1665-1700) una de las primera ofertas para la leva de tropas entre el mundo del bandolerismo regnícola fue la propuesta de levar quinientos caballos, entre los bandidos de Murcia y Valencia, que hizo en 1667 a la reina regente, Mariana de Austria, el capitán de corazas don Juan Martín de Terrazas. Demandaba éste diez patentes de capitán, seis hábitos de caballero y para sí el puesto de teniente general de la caballería. El Consejo de Aragón quería saber antes de dar su visto bueno, quiénes serían los indultados para conocer sus delitos. Por otro lado, algún consejero demandó que si se juntaba realmente aquel contingente que se lo enviase a Flandes o Milán, como ya se había hecho otras veces, para mayor seguridad de aquellos que previamente hubieran podido resultar perjudicados por dichos facinerosos. La reina regente se conformó con este parecer. En octubre de dicho año, el capitán Terrazas estaba dispuesto a dejar fuera de la leva a aquellos inculpados de delitos mayores, si bien se le había señalado que podría extender la leva de los mismos al reino de Aragón. El marqués de Aytona, del Consejo de Regencia, señaló que dada la falta de caballería que había en el ejército de Cataluña, esta leva debería pasar allá, en grupos de cincuenta o de cien, que no se armasen hasta el momento de partir para evitar incidentes, y cobrando sólo tres pagas, pues con cincuenta mil reales de vellón y sesenta mil de plata se podría cubrir su coste. La clave estaba en el beneficio econó-

1. Para Lluís J. Guía «Uno de los frentes de ataque del autoritarismo real, durante los últimos años de la Revolta Catalana y en la década inmediatamente posterior, se presentó bajo el disfraz de la defensa de la justicia y la restauración del orden público; miembros de la pequeña nobleza, pertenecientes al estamento militar, o «ciudadanos» con cargos en el municipio valenciano, fueron acusados de bandoleros o protectores de ellos, y consecuentemente ajusticiados o desterrados». Lluís J. Guía, «Absolutismo y Foralismo en el último período foral valenciano», en E. Sarasa y E. Serrano (coord.), La Corona de Aragón y el Mediterríneo. Siglos XV-XVI, Zaragoza, 1997, pp. 419-432, esp. p. 431.

2. S. GARCía MARTinez, Valencia bajo Carlos II. Bandolerismo, reivindicaciones agrarias y servicios a la monarquía, Villena, 1991. J. Casey, «Bandos y bandidos en la Valencia moderna», en VV.AA., Homenatge al doctor Sehastià Garcia Martinez, 3 vols., Valencia, 1988; vol. I, pp. 407-421. Lluís J. Guía, «La represión del bandolerismo durante el virreinato de Fray Pedro de Urbina (1650-1652)»), en Primer Congreso de Historia del País Valenciano, 4 vols., Valencia, 1976; vol. 3, pp. 411-419. Idem, «La Guerra de Cataluña y el bandolerismo valenciano (1640-1652)», en VV.AA., Actes du Ier Colloque sur le Pays valencien a l'Epoque Moderne, Pau, 1980, pp.117-141.

3. J. REGLÀ, El bandolerisme català del Barroc, Barcelona, 1966. 
mico y las necesidades urgentes a solventar en Cataluña, como vemos. Por otro lado, a Aytona no le preocupaba que los hábitos de caballero fueran a parar a quienes no debían, puesto que se reservaban para «caballeros que por conseguir este honor salgan a servir y ayudarán la leva con sus personas y séquito...». ${ }^{4}$

También sabemos que el bandido Josep Artús aceptó, junto con los treinta y cinco miembros de su cuadrilla, pasar a servir a Nápoles en $1668 .{ }^{5}$

En el transcurso de la Guerra de Holanda (1673-1678), tenemos noticias, de 1675, del envío de bandidos presos de la comarca de la Marina a luchar a Cataluña. ${ }^{6} \mathrm{Y}$ tras el final de la misma, Carlos II permitió la leva en Valencia de contingentes de tropas entre cuadrillas de bandidos para servir fuera de la Península Ibérica. En marzo de 1679 se debían embarcar para Nápoles en el puerto de Alicante cien hombres, todos ellos bandidos, al mando de don Vicente Soler, quien los había reclutado en Elche, si bien el rey no envió a tiempo los cuarenta mil reales que había fijado para aquel negocio como ayuda de costa. Teniendo en cuenta que cada mes la compañía consumía 15.069 reales en salarios, era obvio que interesaba transportarla cuanto antes a Nápoles, pero no deja de sorprender que se pensase en un momento dado remitirlos a su destino vía Cataluña, debiendo hacer el recorrido hasta el Principado a pie. ${ }^{7}$ En julio todavía no se había dispuesto el envío de aquella compañía, cuyos soldados habían quedado encerrados en el castillo de Alicante, con peligro de fugarse dada su extrema necesidad, pues se temía que «llegasen a arrojarse con desesperación por las murallas de dicho castillo». El rey decidió emplear parte del sobrante del último servicio realizado por el reino de ciento ochenta mil reales para pagar el envío de aquella gente a Nápoles. Por otro lado, el 20 de julio llegaron las galeras de la escuadra de Génova a Castellón, donde embarcaron las once compañías del tercio napolitano alojado hasta entonces en el Reino, continuando luego viaje hasta Alicante, donde se reunieron con las dieciocho compañías del tercio lombardo, zarpando para Cádiz conjuntamente el día 28. A su vez, el rey había dado orden que el dinero remanente del servicio citado con anterioridad, el virrey de Valencia debía remitirlo a Cádiz para que sirviese en el viaje hasta Flandes de estas tropas. Es decir, se confiaba, primero, en la existencia de un superávit, y, segundo, que dicho superávit tenía dos destinos previstos. Así, no es de extrañar que aún en agosto la compañía de Soler siguiese encerrada en Alicante. ${ }^{8}$

Mientras coleaba este negocio, el rey dio órdenes de enviar a Milán no los doscientos hombres aprestados por entonces en el Reino, sino que se aumentasen hasta

4. ACA, CA, leg. 571, consulta del C.A., 26-VIII-1667; consultas del C.A., 15 y 21-X-1667.

5. H. KAMEN, La España de Carlos II, Barcelona, 19872, pp. 320-321. S. García Martínez, Valencia bajo Carlos II. Bandolerismo, reivindicaciones agrarias y servicios a la monarquia, Villena, 1991, pp. 168-188.

6. ACA, CA, leg. 563, consulta del C.A., 28-V-1675.

7. ACA, CA, leg. 564, consulta del C.A., 12-XII-1678; virrey de Valencia al C.A., 7-II-1679; consultas del C.A., 19-II y 17-111-1679.

8. ACA, CA, leg. 564, consultas del C.A., 12-V, 15-Vl-1679; virrey al rey, 13 y 20-VI-1679 y consultas del C.A., 15, 26 y 28-VI-1679; virrey al secretario del C.A., 25-VII-1679; virrey al rey, I-VIII-1679. ACA, CA, leg. 571, consulta del C.A., 8-VIII-1679. 
los cuatrocientos, poniendo cuidado en que los bandidos estuviesen incluidos en la remesa. El Consejo de Aragón aprovechó la ocasión, como se ha ido viendo, para demandar medios para remitir a Nápoles la compañía de don Vicente Soler. Cada cosa a su tiempo, vinieron a decir. Pues el coste de vestir, pagar y mantener durante dos meses y enviar finalmente a Milán a cada soldado se estipuló en trescientos cincuenta y ocho reales, y el gasto de trescientas plazas, además de los cien que ya se tenían levados y vestidos, montaba 116.000 reales. De hecho, el virrey hubo de recordar que la compañía de Soler constaba de cien hombres y no de doscientos, como habia insinuado el Consejo de Aragón. Y en enero de 1680 Carlos II ya demandaba una recluta de ochocientos hombres para Milán. El virrey respondió señalando que se decantaba por un tercio de sólo quinientas plazas, aparte de los doscientos ya dispuestos de la Marina, con un coste de entre 185.000 reales y 228.000 reales, según si se contaba sólo el tercio de quinientas plazas o el añadido de las otras doscientas. Poco después se habían recaudado en el Reino, por diversas vías, hasta 117.200 reales y reclutado unos ciento setenta hombres para Italia, que a fines de marzo eran ya cuatrocientos sesenta, gastándose hasta entonces tan sólo 74.301 reales. $^{9}$

Entre tanto, la doble problemática del bandolerismo más la leva de tropas en el Reino se mantenía. Los quinientos primeros se pensaba que podrían levarse en apenas dos meses enarbolando banderas de enganche en las cuatro ciudades del Reino (Valencia, Alicante, Orihuela y Játiva). También desde la corte se remitieron patentes en blanco para otros tantos oficiales que debían cubrir los puestos de capitán de las compañias a levar tanto por el duque de Gandía en sus estados -en junio de 1680 , Carlos II aceptó la salida de Valencia hacia Milán de la cuadrilla del bandido Juan Berenguer, compuesta por ciento veinte sujetos, de los que se dio la filiación completa, que pasarían a servir a Milán durante tres años. ${ }^{10}$ Ya en mayo, el virrey había enviado otros treinta y cuatro a Melilla y Orán. Por entonces, el asesor de la bailía general de Alicante, don Francisco Pascual de Ybarra, quiso saber algo más de la característica de la leva que debía hacer, contestándosele que lo único a lo que debía atender era a «sacar todo el número de vandidos que con su industria pueda reducir a que se embarquen» en dirección a Finale. Don Francisco llegó a ofrecer realizar una leva a su costa, de modo que también se le permitió levantar bandidos para el ejército no sólo en Alicante, sino

9. ACA, CA, leg. 564, consulta del C.A., 31-III-1679; consulta del C.A., 5-IV-1679; virrey al secretario del C.A., 11-IV-1679. ACA, CA, leg. 568, consulta del C.A., 24-I-1680; gobernador de Alicante a don Pedro A. de Aragón, 3-III-1680; consulta del C.A., 28-III-1680; virrey a Carlos II, 7-V-1680 y virrey al rey, 30-XII-1681. Véase, S. García Martínez, "Comisión del virrey duque de Veragua al bandido valenciano Joseph Cases (1679-80), en Primer Congreso de Historia del País Valenciano, 4 vols., Valencia, 1976; vol. 3, pp. 459-472. Por aquellos días, en marzo de 1680 la cuadrilla de fray Vicent Senent aceptó cuatro años de servicio en Milán, dejando hasta diez forajidos como rehenes. (p. 462)

10. Véase, H. KAmEN, La España de Carlos II, Barcelona, 19872, pp. 321-322. Asimismo, aquellos días se consiguió que del grupo de E. Cruanyes aceptasen el trato 59 de sus 112 componentes. Véase, S. García Martínez, Els fonaments del País Valencia modern, Valencia, 1968, pp. 64-65 y S. García Martínez, Valencia bajo Carlos II. Bandolerismo, reivindicaciones agrarias y servicios a la monarquía, Villena, 1991, pp. $213-214$. 
también en cualquier parte donde pudiera hallarlos dispuestos. " En marzo de aquel año, don Francisco Pascual escribía ufano a don Pedro A. de Aragón, presidente del Consejo de Aragón, que había conseguido levar y embarcar doscientos catorce hombres sin las primeras planas,

«...gente tan escogida y famosa qual nunca se ha visto, de suerte que el señor marqués de Ucera me aseguró holgara infinito huviere pasado muestra a vista de V.E. y consejo porque parecía increíble la misma verdad, pues las municiones han sido de mucha gala y provecho, y según todos no habrá entrado compañía igual en el estado de Milán...».

La compañía de Alicante se embarcó rumbo a Valencia, donde ya el virrey tenía aprestadas otras cuatro para su envío a Italia. Allí, el virrey tenía previstos 46.480 reales, además de otros trece mil reales -pero cantidad que no había conseguido reunir del todo, de hecho, en julio se debían 5.114 reales por los gastos realizados- para tales menesteres, una cantidad que se quedó reducida ante el sorprendente éxito de la leva, pues ya se hallaban otros doscientos cincuenta y seis hombres levados en la Ciudad. Es más, el virrey intentó enviar sus capitanes reclutadores a Alicante en vista de la facilidad con la que don Francisco había hecho su leva, cuando, además, desde el puerto alicantino podrían embarcarse todos hacia Italia. El Consejo de Aragón llegó a informar al rey de la salida desde Valencia de ochocientos hombres. ${ }^{12}$ Por una carta de 1683 sabemos que en 1680 se enviaron a Milán desde Valencia novecientos veintinueve hombres con un coste de 207.320 reales. Todo un éxito. ${ }^{13}$

Tenemos que esperar a la finalización del siguiente conflicto, la Guerra de Luxemburgo (1683-1684) para encontrar nuevos datos sobre levas de compañías de forajidos. En mayo de 1685 se pidió permiso para que los ciento dieciocho hombres que comprendían las cuadrillas de Antonio Palacios y Cosme Gil pasasen a servir a Milán por cuatro años a cambio de la remisión de sus condenas. Decía el virrey, conde de Cifuentes, que era una muy buena solución pues en el transcurso del servicio «... muchos mueren, otros quedan en aquellos reynos y los que vuelven vienen enmendados». ${ }^{14}$ También aquellos días se logró que la cuadrilla de M. Oltra, con cincuenta hombres, aceptase un destierro de tres años en Milán sirviendo allí pero sin conceder

11. S. Garcia Martínez, Valencia bajo Carlos II, Villena, 1991, Apéndice, pp. 325-331. ACA, CA, leg. 558, consulta del C.A., 7-V-1680. ACA, CA, leg. 806, Carlos II al presidente del C.A., 19-1-1680; consulta del C.A., 10-l-1680; virrey al rey, 23-I-1680; minuta del C.A. al virrey de Valencia, 6-11-1680; don Pedro A. de Aragón, presidente del C.A., al rey, 3-II-1680; virrey al rey, 13-II-1680.

12. ACA, CA, leg. 806, virrey al presidente del C.A., 5-19-III-1680; don Francisco Pascual de Ybarra al presidente del C.A., 27-III-1680; virrey al secretario del C.A., 12-III-1680; Consejo de Aragón al virrey, 13-III-1680; minuta del C.A. al rey, 26-III-1680; J. Montflorit, pagador de la gente de guerra, al virrey, I-VII-1680; virrey al presidente del C.A., 2-VII-1680.

13. ACA, CA, leg. 568, Pedro de Cortázar a don Jerónimo Dalmao y Casanate, 30-V y 1-VII-1683.

14. ACA, CA, leg. 822, virrey al rey, 22-V-1685 y consulta del C.A., 29-V-1685. ACA, CA, leg. 581, consulta del C.A., 10-VII-1685; virrey al rey, 25-IX-1685. Véase, S. García Martínez, Els fonaments del País Valencia modern, Valencia, 1968, pp. 64-65. 
patente de capitán a Oltra y dejando diez rehenes en la cárcel en Valencia. ${ }^{15}$ Según $H$. Kamen, M. Oltra fue el bandolero valenciano más destacado de la década de 1680, y por dos veces rompió su palabra de aceptar, primero, ir a Milán y, después, a Orán. Pero, como hemos señalado, a la tercera fue la vencida. La trayectoria de Oltra desmintió las palabras antes citadas del virrey Cifuentes, pues al regresar a Valencia volvió a sus antiguas correrías y sólo pudo ser detenido, y posteriormente fallecido, en $1696 .^{16}$

Mientras levantaban aquellas y otras compañías surgió la posibilidad de enviar ayuda a Orán, pero las compañías de bandidos no quisieron separarse, reclamando que todos debían ir a Italia o a Orán. Por su parte, la leva de voluntarios realizada por el capitán Ros

«se le amotinó alegando el engaño de quererlos entrar en Orán cuando ellos habían sentado [plaza] voluntariamente para Nápoles, a que no debió de desayudar la gana del capitán, que con facilidad se me ofreció antes y rezelando que si se embarcase pudiera hacer lo mismo en la mar y violentar los marineros, sobre haber puéstome en conciencia que no podía forzar estos hombres libres, me aparté de este intento, aunque no desconfio la composición de una compañía de infantería para el segundo pasaje de galeras»». ${ }^{17}$

En realidad, uno de los lugares de donde partió más ayuda para socorrer la plaza de Orán durante aquellos años fue, precisamente, el reino de Valencia. ${ }^{18}$ Ya en 1665 se solicitó la leva de una compañía de sesenta plazas para Orán «entre voluntarios y reos de muy leves delitos». Desde entonces, el envío de reclutas valencianas, con notoria presencia de bandidos en sus filas, fue más que notable. En el verano de 1677 se pidieron bastimentos, enviando la ciudad de Alicante ochocientas fanegas de grano, gastando 49.500 reales en total, incluyendo 40.500 reales para una nueva fortificación en la plaza norteafricana. En mayo de 1680 se remitieron treinta y cuatro hombres a Melilla y Orán. Peor fue la situación en 1681, cuando la plaza, tras ser sitiada, perdió a su gobernador y a doscientos hombres en una salida para levantar el cerco. El Consell General acordó el 19 de marzo, por aclamación, enviar doscientos cahíces de trigo y una recluta de cien hombres a la citada plaza. El servicio, que el virrey se encargó de señalar como algo muy útil para toda la costa valenciana, pues la pérdida de Orán permitiría que los corsarios berberiscos molestaran aún más aquellas aguas, costó diez mil reales. En aquella coyuntura se enviaron a dicho presidio las cuadrillas de los bandidos V. Porcell y «Ramonet», con once hombres. ${ }^{19}$ Por otro lado, Alicante y Orihuela también estuvieron dispuestas a contribuir con doscientos cahíces de trigo. Asimismo, el virrey de Valencia invitó a los delincuentes a servir al rey en la ocasión de Orán. El

15. ACA, CA, leg. 581, consultas del C.A., 24-IX y 31-X-1685. S. García Martínez, Valencia bajo Carlos ll. Bandolerismo, reivindicaciones agrarias y servicios a la monarquia, Villena, 1991, pp. 233-234.

16. H. Kamen, La España de Carlos II, Barcelona, $1987^{2}$, p. 321.

17. ACA, CA, leg. 822, virrey al protonotario de Aragón, 17-IV-1685.

18. También se enviaron partidas de bandidos murcianos, como una partida de sesenta forajidos de la zona de Yecla, que pactaron su paso a Orán en 1671. Véase, H. Kamen, op. cit., p. 316.

19. S. García Martínez, Valencia bajo Carlos II. Bandolerismo, reivindicaciones agrarias y servicios a la monarquia, Villena, 1991, p. 226. 
día 20 de marzo, el Consell General estableció que cada hombre de los embarcados para Orán recibiría de las autoridades valencianas cien reales, corriendo por cuenta del rey el pago de sus emolumentos mientras durase su servicio en la plaza norteafricana, establecido en cuatro meses. Y justo cuando se producían las discusiones para el posible envío de parte de la caballería alojada a Orán, en julio de 1687, el Consell General del Reino deliberó ayudar a la plaza enviando mil libras de pólvora fina, mil de cuerda y cien arrobas de plomo. Tras una salida del gobernador, don Diego de Bracamonte, fue derrotado, muriendo, perdiendo su artillería y dos terceras partes de la guarnición. Desde Valencia, significativamente, ni se remitieron tropas ni armas, que, presuponían, serían enviadas por otras ciudades. De todas formas, eran conscientes que si los turcos tomaban Orán, desde dicha plaza «infestarien les nostres costes...». Por ello, Alicante no dudó en despachar cien quintales de pólvora a la plaza en 1688. Y aún en 1689 se cursó una Real Orden, del 27 de octubre, señalando que todos los delincuentes desterrados del reino de Valencia, «...por ser de buena calidad este género de gente, como por las armas de chispa que llevan», debían pasar a reforzar las defensas de Orán..$^{20}$

En todo caso, no se piense que el destino norteafricano era el más peligroso o desagradable para los delincuentes valencianos, Ibiza o, incluso, Mahón también podían serlo. Por ejemplo, en 1688, un bandido valenciano, José Marín, fue condenado a dos años de presidio en Mahón y «...por no poder tolerar el [h] ambre que padecía se fue del, pero en derechura a servir en Cataluña en donde estuvo cuatro años sirviendo en artillería». Es decir, que se preferían los inciertos peligros de la guerra a los seguros del hambre en Menorca. ${ }^{21}$

En el caso de Ibiza, en el transcurso del siglo XVII, progresivamente el recurso a los bandidos valencianos para redondear el número de soldados de su guarnición fue cada vez más claro. El gobernador Juan de Castellví se admiró, en 1625, de los solos cien hombres de infantería, la mitad de ellos ibicencos, que componían el grueso de la guarnición de la isla, cuando debía ser de algo más del doble; de hecho, de haberles borrado la plaza a los naturales, como se debía hacer, no tenía gente suficiente para las guardias nocturnas, en las que se empleaban hasta treinta y tres soldados, debiendo ser relevados en el último cuarto de la noche. Por ello Castellví solicitó el envío desde Valencia de delincuentes que purgasen sus penas en el presidio ibicenco y comple-

20. ACA, CA, leg. 557, consulta del C.A., 12-X-1665. S. García Martínez, Valencia bajo Carlos II..., Apéndice, pp. 325-331, pp. 356 y ss., 415 y 426. ACA, CA, leg. 558, consulta del C.A., 7-V-1680. ACA, CA, leg. 567, gobernador de Alicante al presidente del C.A., 26-VI y 7-VII-1677; consulta del C.A., 19VII-1677. ACA, CA, leg. 567, Carlos II a Pedro A. de Aragón, presidente del C.A., 30-V-1688. ACA, CA, leg. 58I, Carlos II a Pedro A. de Aragón, 25-X-1689; virrey al rey, 8-XI-1689; consulta del C.A., 16-XI-1689.

Desde Murcia se envió a Orán un contingente de cuatrocientos setenta y tres hombres en 1675 que tardaría tres años en regresar. Ante tal exceso no es de extrañar que, a pesar de haber doce prevenciones de envío de tropas a la plaza norteafricana desde Murcia entre 1685 y 1700 , sólo en dos ocasiones, 1685 y 1688 , se remitieron tropas de manera efectiva. Véase, Julio D. Muñoz Rodríguez, Damus ut des. Los servicios de la ciudad de Murcia a la Corona a finales del siglo XVII, Murcia, 2003, pp. 161-163.

21. Véase, ACA, CA, leg. 853, virrey de Valencia al secretario del C.A., 10-XI1-1696. 
tasen su dotación. ${ }^{22}$ No fue el único. Cuando se incorporó al gobierno de Ibiza doce años más tarde, en 1637, Bernardo Salelles, la dotación de la compañía de infantería había quedado reducida a apenas ciento siete hombres y «...porque según la capacidad de las murallas y baluartes, en que hay ocho postas de tres soldados cada una sin el cuerpo de guardia y tres rondas, son menester más soldados, haviéndose señalado 200 plaças en su dotación». La solución, como siempre en estos casos, era apelar al virrey de Valencia y el envío por su parte de delincuentes y vagabundos. ${ }^{23} \mathrm{Y}$ cuando no eran los gobernadores era el Consejo de Aragón. En 1647, por ejemplo, el Consejo pidió el envío de presos de Valencia y Mallorca, pero sin molestar, si era posible, las otras levas que se hacían allá para los ejércitos de Cataluña e Italia. ${ }^{24}$ Aquellos días, el gobernador Leandro Lloris le escribió al virrey de Valencia reclamándole ayuda para Ibiza (hombres y dinero). En cuanto a lo primero, le aseguró el virrey de Valencia a Felipe IV que no había en aquellos momentos presos cuyas penas pudieran ser purgadas sirviendo en la Real Fuerza de Ibiza. ${ }^{25}$

De nuevo en 1652 se le pidió al virrey de Valencia que vaciase las cárceles para hacerle llegar al gobernador de Ibiza toda la gente que pudiese. El virrey de Valencia, duque de Montalto, escribió señalando que si bien el presidio de Ibiza se nutría habitualmente de delincuentes, era a condición de haber cometido éstos un delito proporcionado a tal pena, y en aquellos instantes, en septiembre de 1652, sólo hallaba en las cárceles tres o cuatro de aquellos, no queriendo violentar a la justicia para que suministrase más candidatos al presidio ibicenco, ni podía desviar gente de las levas que se hacían para Cataluña, «...siendo [h]oy aquellas materias las de primera graduación». Pero el Consejo de Guerra insistió que, ante el riesgo de una invasión siempre posible de la isla, se enviasen de las levas para Cataluña (la Ciudad Condal caería en octubre, recordemos) hasta ciento cincuenta hombres a Ibiza. Con todo el virrey, si bien aseguraba tener una compañía de cien hombres lista para remitirla a la isla, no pudo dejar de representar que siendo voluntarios alistados para ir a luchar a Barcelona,

«...se faltaría a la fe pública y al contrato que con ellos se ha hecho remitiéndolos a sitio que cede en pena de delitos, y a parte donde es evidente el riesgo de la vida hallándose la isla contagiosa, y que el achaque más fácil se emprenderá en hombres de este género sustentados de alimentos de poco buena calidad en corta abundancia con que se hallarían condenados a muerte contra su obligación sin culpa».

Pero también habría una consecuencia no menos importante, y es que desde entonces sería más difícil hallar voluntarios en el Reino para servir en el ejército. El rey aceptó aquel punto, pero insistió en enviar a lbiza delincuentes y voluntarios de entre las levas hechas para Cataluña, a su vez voluntarias. El problema acontecido fue que

22. ACA, CA, leg. I.036, consultas del C.A., 6-III y 14-IV-1625.

23. ACA, CA, leg. 1.036, consulta del C.A, 11-II-1638.

24. ACA, CA, leg. 1.037, consultas del C.A., 26-II y 15-V-1647.

25. ACA, CA, leg. 1.043, virrey de Valencia al rey, 30-XI-1648. ACA, CA, leg. 1.037, consultas del C.A., 15-16-[-1649. 
en noviembre, en concreto el día 11, se remitieron en barca a lbiza cincuenta hombres, pero «se alzaron a fuerza viva después de haber herido al patrón y tratando de matar al cabo que los conducía y haciendo volver la barca a tierra, saltaron de ella y huyeron». Poco después, el gobernador de Denia atrapó al jefe del motín y a ocho de los fugados, asegurado el virrey que serían castigados. El virrey despachó de forma inmediata otros treinta y un hombres a bordo de un barco de la Armada que iba a cargar sal para asegurarse que llegarían a su destino. Y en diciembre de 1652 el gobernador Francisco Miguel pudo avisar de la llegada de ciento veinte hombres de Valencia, alcanzando con ellos las tropas de infantería a los doscientos efectivos, pero augurando que pronto se perderían si no se enviaban rápidamente recursos,

«y en diez meses que asisto en este gobierno no [h] llegado ningún socorro de trigo ni dinero haviendo estado en esa Corte persona solicitándolo, ya, Señor, no tengo más que decir a V. M. de lo que he ponderado por otras añadiendo a[h]ora que dudo que de ningún sitio sc puedan contar las lástimas que aquí se oyen».

El Consejo de Aragón pidió encarecidamente al rey asistencias para Ibiza. ${ }^{26}$

Desde entonces, parece que la dotación de infantería de Ibiza pasó a estar cubierta casi exclusivamente por este tipo de reclutas. En 1662, aseguraba el gobernador, Rodrigo de Borja, futuro virrey de Mallorca, que la guarnición estaba compuesta entonces sólo por cien hombres, enviados casi todos por los virreyes de Valencia y Mallorca a purgar sus penas allá, sólo permaneciendo los que se casaban, «y éstos no saben de guerra más de lo que acá han oído. Los paisanos tienen valor y serán de provecho al exemplo de soldados veteranos, pero por sí solos se puede esperar poco, y nada para los puestos de afuera...». Por ello reclamaba trescientos soldados veteranos como mínimo y su correspondiente dinero para mantenerse, pues en Ibiza, como en Ciudadela, no se les daba el pan de munición. ${ }^{27}$ Desde luego, no era un destino cómodo.

En septiembre de 1668 solicitó el gobernador de Ibiza, Jerónimo García, el envío de ciento cincuenta soldados «...viejos que han desquadernado del exército», es decir, reformados, con la idea de que en el mismo barco que los trajese se llevase a otros tantos de los que se hallaban allá de presidio, pues estando éstos últimos destinados en Ibiza «...por delitos que han cometido, hazen cada día muchos insultos, no bastando el castigo, ni el freno, para que se mejore su mal natural». El Consejo de Aragón convino en enviarlos a Orán, pues tener toda la guarnición de gente facinerosa no era conveniente. La reina regente estuvo de acuerdo. ${ }^{28}$

26. ACA, CA, leg. 1.038, Felipe IV al vicecanciller del Consejo de Aragón, 22-VI-1651 y 29-11-1652; vicecanciller del Consejo de Aragón al rey, 30-IX-1652; gobernador Miguel al rey, 16-XII-1652; consulta del C.A., 18-I-1653. ACA, CA, leg. 1.044, virrey de Valencia al rey, 24-26-XI-1652.

27. ACA, CA, leg. 1.043, gobernador de lbiza al vicecanciller del Consejo de Aragón, 26-VIII-1662.

28. ACA, CA, leg. 1.038, consulta del C.A., 10-VII-1668. ACA, CA, leg. 1.043, gobernador a la regente, $10-$ VIII-1668. ACA, CA, leg. 1.038, consulta del C.A., 10-IX-1668. ACA, CA, leg. 1.043, gobernador interino J. Balansat a la regente, 29-I-1669. Y otro riesgo es que pasase un capitán reclutador por allí camino de Italia. Es lo ocurrido en 1692, cuando el capitán Altamira, que llevaba una compañía a Nápoles desde Valencia, intentó sumar uno más a la lista, reclutándolo en Ibiza, pero fue descubierto por el gobernador 
Su sustituto definitivo, el maestre de campo mallorquín Francesc Truyols, explicó al Consejo de Aragón que si el virrey de Valencia no recibía los cuarenta mil reales prometidos no enviaría una recluta de cien hombres a la isla, sino que se limitaría, como había hecho, a mandar algunos condenados que sólo servían para robar y poco más. $\mathrm{Y}$ es que el primer informe de Truyols comentando la situación de la isla fue desalentador. Explicaba que la guarnición de Ibiza debía sacar de su sueldo los gastos comunes de manutención, alojamiento, vestidos, hospital, etc. Pero Truyols se quejaba, asimismo, de su ínfima calidad, sin disciplina ni sapiencia militar alguna, «... procediendo la mayor parte dellos de los vagamundos, vandidos y gente perdida de diferentes Reynos, de donde procuran los virreyes para limpiar sus provincias remitirlos a este presidio... ${ }^{29}$

En la década de 1680 el gobernador F. Vegués solicitaba una dotación de hasta doscientos cincuenta hombres de calidad para defender las murallas de Ibiza, cuando apenas le ofrecían desde Valencia ciento treinta y siete - de los cuales treinta y siete eran condenados. El virrey de Valencia acabó por dejar en el aire la recluta de un centenar de hombres para Ibiza al no recibir los veintidós mil reales prometidos para tal fin, cosa que tampoco acabó de asombrar al gobernador Vegués que le pidió, en todo caso, los treinta y siete condenados que tenía prevenidos. ${ }^{30}$ Lo más divertido del asunto fue que cuando el Consejo de Aragón volvió a reiterar al virrey de Valencia la petición de envío a Ibiza de ciento cincuenta hombres en 1685 , éste terminó por alegar que no sólo no contaba con medios, sino ni siquiera con presidiarios, pues los treinta y siete dispuestos con anterioridad los había remitido ya a otras partes. ${ }^{31}$ Ello parece ser cierto, pues hasta fines de 1697, una vez terminada la Guerra de los Nueve Años, no tenemos noticias del envío de presos valencianos a Ibiza, cuando se le remitieron al gobernador de Ibiza catorce. ${ }^{32}$ Sin duda la actitud del virrey Castel Rodrigo estuvo detrás de dicha circunstancia.

$Y$ es que en la Valencia de aquellos años, la persecución exitosa o no del bandidaje se transformó en una de las principales causas para favorecer a algunos virreyes, como el conde de Cifuentes, para el que, fenecido su trienio como virrey, los jurats de Valencia reclamaron al rey la concesión de un segundo mandato. Los valencianos estaban admirados de su disposición personal, su desinterés en el ejercicio del cargo, y su lucha contra los bandidos que infectaban el Reino, quienes, tras su labor, por entonces se hallaban «...en Nápoles al Real servicio de V. Magt.». ${ }^{33}$ Mientras que, por otro

Morro y Pastor, que alegó la necesidad extrema de los hombres de la isla para defenderse de las amenazas constantes del enemigo. Véase, ACA, CA, leg. 1.044, gobernador de Ibiza al rey, 16-II-1692.

29. ACA, CA, leg. 1.037, gobernador Truyols al Vicecanciller del C.A., 15-IX-1671. ACA, CA, leg. 1.037, gobernador a la regente, $25-\mathrm{XI}-1671$.

30. ACA, CA, leg. 1.044, gobernador Vegués al rey, 5-VI-1684.

31. ACA, CA, leg. 1.038, cartas del gobernador de Ibiza, J. Bayarte al C.A., 4 y 20-IX-1684. ACA, CA, leg. 1.038, gobernador de Ibiza al presidente del C.A., 5-Il-1685; consultas del C.A., 23-II y 6-III-1685.

32. ACA, CA, leg. 851, virrey de Valencia al conde de Vilafranca, 29-X-1697.

33. ACA, CA, leg. 620, jurats de Valencia a Carlos II, 18-XII-1685. 
lado, en su momento se acusará al virrey Castel Rodrigo de una cierta dejadez con los bandidos en los años noventa, cuyas cuadrillas habían vuelto a incrementar su número y entraban impunes en los arrabales de Valencia, incluso. El marqués de Castelnovo, de Consejo de Aragón, ponía como ejemplo de eficacia al conde de Altamira, virrey durante el trienio de 1688 a 1690 , quien terminó con las cuadrillas de bandidos en Valencia, una tierra que «...como produce trigo y cebada brota también delinquentes, pues la semilla destos es casi inextinguible en todo aquel distrito». Por último, Castelnovo culpaba al virrey de usar las componendas económicas para castigar a los bandidos apresados, pasando de doscientas las personas tan levemente condenadas y pedía a Carlos II que no creyese simplemente en sus palabras, sino que buscase de manera reservada los testimonios oportunos en el Reino. ${ }^{34}$ Lo cierto es que durante sus años de gobierno en Valencia de Castel Rodrigo, de 1691 a 1696, apenas hemos encontrado referencias al envío de compañías de bandidos a luchar en los ejércitos del rey. La excepción, quizá conectada con las primeras noticias sobre el malestar en la comarca de la Marina, es decir, la famosa Segunda Germanía, hizo que el virrey Castel Rodrigo, con la ayuda del obispo de Tortosa, promoviese el envío durante seis campañas al ejército de Milán de las cuadrillas de los bandidos Baltasar Bel y José Romero, siendo indultados de todos sus delitos al finalizar el servicio. ${ }^{35}$

\section{EL BANDOLERISMO EN EL REINO DE MALLORCA Y LA RECLUTA DE TROPAS}

En la Mallorca de Carlos II, el primer virrey del reinado, el valenciano Rodrigo de Borja, se enzarzó en una guerra particular: la lucha contra el bandidaje. Explicaba a fines de 1666 que todavía le quedaba una cuadrilla de once facinerosos por detener, pero se comprometía, si había prisa, a «...embarcar hasta doscientos hombres concurriendo con muchos bandidos y malhechores que se han sacado de las Iglesias que están en el castillo de Bellver, gozando de la inmunidad eclesiástica». El Consejo de Aragón dio su visto bueno a dicha recluta, pero con los bandidos sobre los que no pesara una condena de muerte o a galeras. ${ }^{36}$

A partir de enero de 1667, la reina regente, Mariana de Austria, había solicitado al reino de Mallorca una leva de cien artilleros mallorquines para servir en los presidios de la Península, así como un refuerzo de tropas para el tercio mallorquín de la Armada, que podían ser bandidos, y, por último, un nuevo servicio que consistiría en levar y pagar durante una campaña un tercio de cuatrocientos hombres para enviarlo a Cataluña ${ }^{37} \mathrm{Al}$ comenzar la guerra con Francia, también el virrey de Mallorca recibió orden de estar al tanto de las necesidades de Ibiza y Menorca. En julio de aquel año,

34. ACA, CA, leg. 581, virrey al rey, 12-VIIl-1691; consulta del C.A., 29-VH1-1691.

35. ACA, CA, leg. 581, consulta del C.A., 10-VI-1693; virrey al secretario del C.A., 19-V y 2-VI-1693.

36. ACA, CA, leg. 991, consulta del C.A., 6-VII, 19-XI-1666 y 14-I-1667.

37. En realidad, el Consejo de Aragón recordó que el maridaje en las Baleares montaría poco más de esos 3.000 escudos y que lo que no se podría hacer era acudir a una leva de artilleros en Mallorca, cuando 
el virrey informaba que salía de Mallorca una compañía de setenta y cinco plazas para reforzar la Armada, así como noventa y tres forajidos que se enviaron a los puertos de Cartagena y Málaga. ${ }^{38}$

Un asunto que trajo cola fue la leva del tercio ofrecido por don Nicolás de Santacília. La leva del tercio, que debía ser de quinientas plazas pagadas por el rey, que había dotado con ochenta mil reales dicho negocio, comenzó a ser gestionada por el virrey marqués de Fuenclara, quien llegó a levar cieno doce plazas, siendo sustituido a mediados de 1675 por B. Pardo de la Casta, marqués de la Casta. Recién llegado al puesto, y habiendo un gran problema con los bandidos en Mallorca, el virrey pidió a los miembros de la Real Audiencia si era a propósito enviarlos a Mesina con el tercio de Nicolás de Santacília. Algunos miembros respondieron que los delitos cometidos eran tan graves, hasta haber disparado en sagrado, y la pena tan mínima, pues en apenas dos años regresaban a la tierra después de realizar grandes fechorías, que no estaban muy de acuerdo en enviar bandidos al ejército para remisión de sus penas. Pero el punto de vista del maestre de campo Santacília era muy diferente, pues deseaba levantar el mayor número de gente y el virrey lo secundaba, añadiendo éste que «...se hecharían redes para que también se embarcasen los vagamundos de que abunda esta ciudad». Pero cuando el virrey conoció más a fondo la realidad, ya no dio tantas facilidades para llenar las filas del tercio Santacília de bandidos. El virrey supo que éste le había hecho la vida imposible a un caballero de suposición del reino que tenía patente de oficial del tercio concedida por el anterior virrey, conde de Fuenclara. Todo el problema surgió porque dos ministros de la Real Audiencia le registraron una quinta a Santacília donde se ocultaban facinerosos. Por ello, el virrey pedía dar un correctivo a Santacília y un escarmiento a todos los caballeros que protegían a los bandidos. Nicolás de Santacília defendió su posición diciendo que había conseguido levar hasta doscientos veinte voluntarios antes del 18 de mayo, pero que después, con la siega, ya era muy difícil encontrar gente, aunque continuaría; si bien el actual virrey no quería ahora darle licencia para levar bandidos, cuando antes la tenía del conde de Fuenclara. Además, en los últimos treinta años el procedimiento había sido aquel, pues en 1644 el virrey don Lope de Francia «...dio permiso a todos los vandidos pregonados muertos o vivos de una y otra parcialidad de perdonarles señalándoles tiempo para que se diesen...» y muchos de ellos no quisieron hacerlo a pesar de la magnanimidad. En 1646, su padre, don Pedro de Santacília, levantó un tercio para el sitio de Lleida, o el del conde de Santa María de Formiguera de 1653, o las compañías para Sicilia, o en el tercio de don Josep de Borja, siendo virrey su padre, don Rodrigo de Borja, quien emprendió una gran acción contra los bandidos con gran gasto, por otro lado, y en todas esas ocasiones se hizo indulto y se permitió la salida de bandidos del Reino. La respuesta de la reina regente, con la revuelta de Mesina en plena ebullición, fue decirle a su virrey que debía ajustar

ya se había comprometido aquel dinero para una recluta con destino al tercio de la armada y para las fortificaciones de Cataluña. ACA, CA, leg. 1.018, consulta del C.A., 26-V-1667.

38. ACA, CA, leg. 564, consulta del C.A., 26-V-1667. ACA, CA, leg. 992, virrey a la regente, 3-V11-1667. ACA, CA, leg. 992, la regente al virrey, 15-V-1667. 
la leva tanto de bandidos, presos de las cárceles y vagabundos hasta poner el tercio en las quinientas plazas señaladas, siendo la solución impedir que saliesen más barcos corsarios de Mallorca hasta que no se consiguiese el refuerzo para el ejército hispano de Mesina. ${ }^{39}$ Para entonces, el virrey marqués de la Casta ya se había olvidado de su idea inicial de que, al calor de aquella leva, el Reino contribuyese con otro tercio de cuatrocientas plazas. ${ }^{40}$

Entre julio y septiembre de 1675, el número de alistados pasó de 293 hasta las 386 plazas, más veinticinco voluntarios que les siguieron, así como otras setenta plazas que el virrey tenía levadas, pidiendo por entonces al Consejo de Aragón medios para poder enviar a su destino a dichos hombres y que no hiciesen más gasto en Mallorca. En principio, seis bajeles de la Armada debían transportar estas tropas a Mesina, habiéndosele prometido para la leva 79.750 reales al virrey, pero éste sólo había recibido por entonces $9.600{ }^{41}$

De Mallorca salió, finalmente, el tercio del maestre de campo Nicolás de Santacília a la Guerra de Mesina en octubre de 1675. Según L. Ribot, oficialmente el tercio de setecientas plazas (para nosotros de quinientas) se vio reducido a un servicio menor, tan sólo trescientos hombres; pero, una vez hecha in situ la comprobación de las calidades de aquellos hombres, se verificó que noventa plazas correspondían a niños de diez a doce años, quedando muy rápidamente reducida la tropa a 181 efectivos. También hay otra fuente que fija en 372 el número de soldados efectivos enviados desde Mallorca, y setenta y uno los excluidos por su corta edad. Estas fuerzas huirían en su totalidad de la guarnición de Naso, como hicieron otras agrupaciones, debido al desgaste tremendo de la campaña de 1676. Ante el escándalo suscitado por el enorme número de plazas de menores, el secretario de la capitanía general de Mallorca, V. Maymó, fírmó el 21 de marzo de 1676 un certificado dando fe de que en la leva del tercio Santacília, «que se embarcó a 6 de agosto 1675 no asentó plaza ningún soldado que no fuese de catorse años y los de esta edad no fueron más de quarenta y uno conforme está confirmado en las listas de dicha leva». ${ }^{42}$

\section{EL CASO DE LA COMPAÑÍA DE GASPAR IRLES (1677)}

En noviembre de 1677, Gaspar Irles había obtenido patente de capitán si lograba reunir hasta cien de sus seguidores en las parcialidades habidas en Elche y marchaban a Nápoles a servir en el tercio de españoles de dicho reino. Irles se presentó en Alicante con cuarenta y seis hombres asegurando que pronto llegaría a los cien, reclamando su

39. ACA, CA, leg. 992, regente al virrey, 4-VI-1675. ACA, CA, leg. 991, virrey a la regente, 9-VI-1675, incluye un memorial de N. de Santacília. ACA, CA, leg. 991, regente al virrey, 26-VI-1675.

40. ACA, CA, leg. 73, borrador de carta del virrey al C.A., sin fecha, pero posterior a junio de 1675 .

41. ACA, CA, leg. 992, virrey al vicecanciller del C.A., don Melchor de Navarra, I-VII-1675. ACA, CA, leg. 992 , virrey a la regente, $20-\mathrm{IX}-1675$.

42. Luis RIBOT, La Monarquia de España y la Guerra de Mesina (1674-1678), Madrid, 2002, pp. 169 y 468. Véase ACA, CA, leg. 992, certificado de V. Maymó, 21-III-1676. 
patente y el cobro de la ayuda de costa suficiente para mantenerse allá hasta que reuniese los mencionados cien hombres y se encontrase un barco que los llevase a Nápoles. El gobernador de Alicante, barón de Boil, además de aquellas órdenes, recibió sólo 6.500 reales para el negocio, si bien se le demandó cuál sería el coste final de la operación: 14.400 reales de plata fue la respuesta. El virrey de Valencia advirtió que él no tenía caudal alguno sobrante que enviar, de manera que el Consejo de Guerra presionó al de Hacienda para que se remitiese efectivamente la cantidad antes consignada. ${ }^{43}$

En primera instancia se pensó en enviar esta gente a Cádiz para embarcarlos allá rumbo a Italia en dos fragatas de cuenta que, al mando de don Valentín Pérez, habían llegado allá procedentes de los Países Bajos y con destino a Nápoles; pero, finalmente, se decantaron por su envío a Ibiza, donde serían mantenidos con el dinero prevenido para la tripulación (ciento veinte hombres a reclutar en Mallorca y Barcelona) de la fragata que ultimaba el gobernador $\mathrm{F}$. Truyols. La idea era que las dos fragatas que iban de Cádiz a Italia pasarían igualmente por Ibiza para realizar el viaje junto con la fragata de Truyols. El Consejo de Guerra tuvo la prevención de recomendar que la compañía de Irles, «respecto de ser forajida», no viajase junta a partir de Ibiza, sino que se repartiese entre las tres fragatas, recomendando al rey la prevención de medios suficientes. ${ }^{44}$ Pero el Consejo de Guerra, tras recibir noticia de que, en realidad, no había dinero alguno prevenido en Ibiza, se apresuró a escribir al gobernador de Alicante para que proveyese a la compañía de Irles -que entre tanto alcanzó los ochenta hombres- con cinco mil reales, pero que los enviase inmediatamente a Ibiza, y al gobernador Truyols se le dijo que se enviaría lo necesario, dándole órdenes severas para que encerrase en el castillo o donde fuera seguro a aquella gente, de buena calidad, para que no escaparan y, sobre todo, para que no volvieran a Elche. ${ }^{45} \mathrm{El}$ gobernador de Alicante pudo alquilar dos embarcaciones, con un coste de 1.560 reales de plata, y el 21 de diciembre envió la compañía de Irles a Ibiza compuesta, al final, por 155 hombres cuyo mantenimiento en Alicante y posterior traslado hasta Ibiza costaron 13.150 reales. Como sólo se le habían enviado los 5.000 reales señalados antes, el Consejo de Guerra insistió en que se le remitiese la diferencia, conseguida a crédito, decía el gobernador, barón de Boil, y que no se olvidase enviar medios al gobernador de Ibiza para mantener aquella gente hasta su paso a Italia. ${ }^{46} \mathrm{Y}$ Avisará el veedor del presidio de Ibiza, N. Arda y Moxica, que el día 24 de diciembre llegaron a Ibiza los 142 hombres de la compañía del capitán Irles levantada en Elche. ¿Hubo alguna deserción o, simplemente, una cierta desidia a la hora de comprobar los datos y contrastarlos por parte del veedor? ${ }^{47}$

Transcribimos a continuación la filiación de los componentes de la compañía de Gaspar Irles:

43. AGS, GA, leg. 2.376, consulta del C.G., 17-XI-1677.

44. AGS, GA, leg. 2.376, consulta del C.G., 20-XI-1677.

45. AGS, GA, leg. 2.376, consultas del C.G., 29-XI-1677.

46. AGS, GA, leg. 2.409, gobernador de Alicante al secretario del C.G., 20-X11-1677; gobernador de Alicante al rey, 27-XII-1677; consulta del C.G., 7-I-1678.

47. AGS, GA, Leg. 2.409, consulta del CG, 21-I-1678. 
«En la ciudad de Alicante, Reino de Valencia, a los veinte y cinco días del mes de noviembre año del Señor de Mil Seiscientos Setenta y Siete por su merced del noble don Pedro Boil de Arenós, noble de Aragón, Varón de Boil y de Borriol, señor de los lugares de Alfafar y Masanasa, mayordomo de su Alteza el Señor Don Joan, del Consejo de su Magd. Portanvezes del General Gobernador y lugarteniente de Capitán General de la ciudad de Orihuela y Reino de Valencia de Sexona a esta parte fue hecho el pie de lista de la compañía del capitán Gaspar Irles cuio tenor es el que se sigue

Pie de lista de los soldados de la compañía del capitán Gaspar Irles

Gaspar Irles, capitán.

Fray Miguel Puigserver, capellán de la compañia.

Guillem Francisco Campos, hijo de Joan, del lugar de Escarrilla, de 32 años, mellado, delgado de cuerpo, pelo negro, sargento.

Paje de Gineta.

Dos tambores

\section{Soldados}

1 Josep Irles, hijo de Gregorio, natural de Elche, de $<\mathrm{h}>$ edad de 32 años, buena estatura, pelo castaño.

2 Lucas Poveda, hijo de Cristóbal, de Villena, de 32 años, alto de cuerpo, pelo negro.

3 Baltasar Poveda, hijo de Cristóbal, natural de Villena, de 20 años, lampiño, pelo negro, de mediana estatura.

4 Jaime Curi, hijo del mismo, natural de Frechilla, de 38 años, buena estatura, mellado y con un lunar encima el bigote de la parte izquierda.

5 Miguel Menargues, hijo de Joan, natural de Murcia, de 30 años, buena estatura, pelo castaño largo.

6 Ginés Menargues, hijo de Joan, de Murcia, de 40 años, buena estatura, bigote negro.

7 Francisco Menargues, hijo de Joan, de Murcia, de 20 años, bajo de cuerpo, pelo castaño con poca barba.

8 Marco Ortuño, hijo del mismo, de Almasarrón (¿Almazarrán?), de 38 años, cerrado de barba, buena estatura, pelo negro.

9 Josep Menor, hijo de Vicente, de Xàtiva, de 24 años, buena estatura, pelo castaño largo.

10 Josep Dolera, hijo de Bartolomé, de Alicante, de 19 años, mediana estatura y sin pelo de barba.

11 Antonio Galiana, hijo del mismo, de Xixona, de 21 años, mediana estatura, delgado de cuerpo, pelo castaño.

12 Lorenzo Lapiedra, hijo del mismo, de Alicante, de 19 años, sin pelo de barba.

13 Antón Julián, hijo de Diego, de Segorbe, de 30 años, buena estatura, lampiño, pelo castaño.

14 Antonio Peral, hijo de Joan, de Arenys de Mar, buena estatura, pelo castaño crespo con poca barba.

15 Josep Sierra, hijo del mismo, natural de Barcelona, de 20 años, mediana estatura, poca barba.

16 Antonio Ribas, hijo de Joan, de Mallorca, de 25 años, mediana estatura, con una verruga en la frente con poco pelo y barba.

17 Antonio Grau, hijo de Andrés, de Mallorca, de 40 años, mediana estatura, poco pelo.

18 Joan Miralles, hijo de Francisco, de Cataluña, de 27 años, mediana estatura, poco pelo negro. 
19 Josep Carserán, hijo de Pedro, de Barcelona, de 22 años, buena estatura, con un golpe en la frente, pelo castaño.

20 Nicolás Oliver, hijo de Antonio, de Alicante, de 18 años, buena estatura, sin pelo de barba.

21 Diego González, hijo de Josep, de Alicante, de 17 años, buena estatura, sin pelo en cabeza y barba.

22 Antonio Violate, hijo de Francisco, de la ciudad de Girona, de 25 años, buena estatura, pelo castaño.

23 Bautista Goda, hijo del mismo, de Albaida, de 16 años, con una cicatriz en el carrillo izquierdo sin pelo en la barba.

24 Josep Roio, hijo del mismo, de Valencia, de 15 años, sin pelo en la barba y de mediana estatura.

25 Josep Sala, hijo de Gaspar, de Valencia, de 15 años, de mediana estatura y sin pelo de barba.

26 Josep García, hijo de Nicolás, de las Casas de Ves, en Castilla, de 15 años, mediano de cuerpo, sin pelo en la barba.

27 Pedro Feliú, hijo de Pedro Joan, de Benis[s]a, de 18 años, mediana estatura, sin pelo de barba, amarillo de cara.

28 Pedro Gómez, hijo de Pedro, del Campillo de Altobuey, de 15 años, mediana estatura, pelo negro, cerrado de barba.

29 Gregorio Llobregat, hijo del mismo, de Elche, de 19 años, buena estatura, sin pelo en la barba.

30 Josep Catalán, hijo de Gaspar, del lugar de Picany[a], de 34 años, buena estatura, moreno de cara, pelo negro crespo.

31 Blas del Olmo, hijo del mismo, de Xàtiva, de 17 años, buena estatura, sin pelo en la barba.

32 Josep Planes, hijo de Miguel, de Xàtiva, de 22 años, buena estatura, poco pelo castaño, lampiño.

33 Roque Castillo, hijo de Tomás, natural de Escatrón, mediana estatura, sin pelo en la barba, pelo castaño.

34 Joan de Villanueva, hijo de Joseph, de Vicorgo (¿Vicorto?), de 19 años, mediana estatura, poco pelo.

35 Bautista Aranda, hijo de Joan, de Valencia, de 15 años, mediana estatura, sin pelo, moreno de cara.

36 Félix Roig, hijo de Icacio, de Valencia, de 16 años, mediano de cuerpo, sin pelo en la barba.

37 Vicente Guillén, hijo de Gaspar, de Alcoy, de 20 años, mediana estatura, sin pelo de barba.

38 Josep Simión, hijo de Josep, de Albalat de Pardines, de 15 años, delgado de cuerpo $y$ sin pelo en la barba.

39 Josep Garrido, hijo de Joan, de Orcha (l'Orxa), de 21 años, buena estatura, pelo castaño y lampiño.

40 Damián Gil, hijo de Francisco, [Tavernes de la] Valldigna, de 16 años, mediano de cuerpo, picado de viruelas, sin pelo en la barba.

41 Jaime Cruañes, hijo de Joan, de Xàtiva, de 24 años, buena estatura, pelo castaño, cerrado de barba.

42 Miguel Sierra, hijo de Josep de ¿Villaondara?, de 24 años, buena estatura, pelo negro, cerrado de barba. 
43 Josep de Arela, hijo de Francisco, de Murcia, de 28 años, buena estatura, pelo negro, colorado de cara.

44 Francisco Cano, hijo de Alonso, de Baza, de 26 años, buena estatura, delgado de cuerpo.

45 Pedro Cano, hijo del mismo, de Murcia, de 25 años, buena estatura, pelo negro, un lunar en el carrillo izquierdo.

46 Josep Garre, hijo de Joan, de Murcia, de 20 años, buena estatura, cabello castaño oscuro.

47 Gaspar Escudero, hijo de Joan, de Murcia, de 24 años, buena estatura, cabello castaño.

48 Francisco Guillén, hijo del mismo, de ¿Las Alguesas?, de 27 años, alto de cuerpo, moreno de cara.

49 Pedro Escudero, hijo de Martín, de Murcia, de 22 años, buena estatura, sin pelo de barba, cabello castaño claro.

50 Josep López, hijo del mismo, de Murcia, de 29 años, buena estatura, pelo castaño.

51 Francisco Perea, hijo del mismo, del Espinardo, de 25 años, buena estatura, pelo castaño oscuro.

52 Francisco Hernández, hijo de Pedro, del Espinardo, de 20 años, delgado de cuerpo, pelo castaño oscuro.

53 Joan Nadal, hijo del mismo, de Lérida, de 21 años, buena estatura, colorado de cara, pelo castaño claro.

54 Pedro Rubio, hijo de Antón, de ¿Avanilla?, de 22 años, buena estatura, lampiño, pelo negro.

55 Joan Esteban, hijo de Joan, de Yecla, de 19 años, mediana estatura, sin pelo en la barba.

56 Josep Perez, hijo de Ginés, de Orihuela, de 20 años, buena estatura, sin pelo en la barba.

57 Sebastián López, hijo de Domingo, de 24 años, mediana estatura, bermejo de cara, pelo castaño, de Orihuela.

58 Josep Cariñana, hijo de Miguel, de ¿Billus?, de 20 años, buena estatura, sin pelo en la barba.

59 Francisco Garriga, hijo de Mateo, de Alicante, de 23 años, cerrado de barba, mediana estatura.

60 Silvestre Vernís, hijo de Bernardo, de Perpinán, de 27 años, buena estatura, algo calvo.

61 Ginés de Requena, hijo de Alonso, de Caudete, de 16 años, mediana estatura, sin pelo en la barba.

62 Luis Ferrando, hijo de Gaspar, de Concentaina, de 17 años, buena estatura, sin pelo en la barba, cabello castaño.

63 Pedro Blasco, hijo de Pedro, de Alicante, de 20 años, buena estatura, sin pelo de barba, cabello castaño.

64 Diego de Cases, hijo de Miguel, de La Roda, de 19 años, mediana estatura, moreno de cara y sin pelo en la barba.

65 Gregorio Cortés, hijo de Joan, de Xixona, de 30 años, buena estatura, pelo negro.

66 Joseph Palles, hijo de Pedro, de ¿Calandria?, de 20 años, buena estatura, pelo castaño y sin pelo en la barba.

67 Joan Corona, hijo del mismo, de Ayora, de 20 años, buen cuerpo, pelo castaño y sin pelo en la barba. 
68 Domingo Hernández, hijo de Joseph, de Alicante, mediana estatura, pelo castaño claro y sin pelo en la barba.

69 Joan Ortiz, hijo de Ramón, de ¿Valldarorles?, de 22 años, moreno de cara, buena estatura y sin pelo en la barba.

70 Ginés Bordera, hijo de Pedro, de Elche, de 16 años, mediana estatura, sin pelo en la barba.

71 Josep Pastor, hijo del mismo, de Alicante, buen cuerpo, poca barba, pelo castaño.

72 Joaquim Sala, hijo de Vicente, de Muchamiel, de 28 años, de buen cuerpo, moreno de cara, pelo crespo.

73 Jerónimo Carratalá, hijo de Miguel, de Muchamiel, de 24 años, buen cuerpo, pelo castaño claro.

74 Jacinto Gozalbes, hijo de Nicolás, de Alicante, de 20 años, de buena estatura, pelo castaño y lampiño.

75 Antonio Andrés García, hijo de Simón, de Granada, de 20 años, mediana estatura y poca barba, pelo negro.

76 Luis Pérez, hijo de Joseph, de Alicante, de 20 años, buena estatura, pelo castaño.

77 Miguel Cases, hijo de Gregorio, de Concentaina, de 20 años, mediano de cuerpo, lampiño.

78 Joan Amorós, hijo de Joan, de Biar, de 18 años, mediano de cuerpo y sin pelo en la barba.

79 Carlos Camberos, hijo de Antonio, de Málaga, de buena estatura, moreno de cara, lampiño.

80 Domingo Arcaina, hijo del mismo, de Xàtiva, de 30 años, de mediana estatura, pelo castaño, poca barba.

81 Lorenzo López, hijo de Tomás, de Sant Joan, de 22 años, mediano de cuerpo, lampiño.

82 Pedro Borrent, hijo de Francisco, de Xàtiva, de 22 años, buena estatura, pelo crespo, castaño.

83 Joan Gilart, hijo de Jaime, de Elche, de 20 años, buena estatura, pelo castaño y sin pelo en la barba.

84 Alfonso Irles, hijo de Joseph, de Alicante, de 20 años, mediana estatura, cabello crespo y sin pelo en la barba.

85 Josep Amengol, hijo de Francisco, de Alicante, de 18 años, mediano de cuerpo, pocos cabellos y sin pelo en la barba.

86 Tomás Castelló, hijo de Mateo, de Onteniente, de 20 años, sin pelo en la barba y mediano de cuerpo,

87 Bautista Soler, hijo del mismo, de Elche, de 22 años, buena estatura, cerrado de barba.

88 Pedro Giner, hijo del mismo, de Onteniente, de 38 años, alto de cuerpo, pelo crespo.

89 Pedro Martínez, hijo de Alonso, de Ayora, de 26 años, mediano de cuerpo, pelo negro largo.

90 Josep Ferrer, hijo de Domingo, de 36 años, mediana estatura, poco pelo, colorado de cara.

91 Felipe Alcaraz, hijo de Joseph, del lugar de Sant Joan, de 16 años, de mediana estatura, mellado y pelo castaño.

92 Francisco Gómez, hijo del mismo, de Elche, de 16 años, mediana estatura, mellado, pelo negro. 
93 Francisco Fuster, hijo de Miguel, de la villa de Benicarló, de 45 años, de buena estatura y cano.

94 Josep Fuster, hijo de Francisco, de Benicarló, de 18 años, mediana estatura, pelo castaño.

95 Jerónimo Pastor, hijo de José, de Castellón de Xàtiva, de 17 años, mediana estatura, pelo castaño y con una señal sobre el ojo izquierdo.

96 Lorenzo Samella, hijo de Francisco, de Benicarló, de 17 años, mediana estatura y sin pelo de barba.

97 Francisco Fenbil, hijo del mismo, de Elche, de 22 años, mellado, buena estatura, pelo castaño.

98 Miguel Vidal, hijo de Gaspar, de Villa Real, de 40 años, barba negra, buena estatura, pelo castaño.

99 Blai Cortés, hijo de Francisco, de Alcalá de Jovada, buena estatura, barbirrojo, de 25 años.

100 Francisco Molins, hijo del mismo, de Valencia, de 20 años, poca barba, mediana estatura, moreno de cara, pelo negro.

En 26 de dicho mes de noviembre sentaron plaza los soldados siguientes

101 Pascual Navarro, hijo de Tomás, de Valencia, de 17 años, rubio de cara, mediana estatura y sin pelo de barba.

102 Josep Requena, hijo de Andrés, de Mi[s]lata, Reino de Valencia, de 30 años, buena estatura, pelo y barba rubio.

103 Fernando Sandoval, hijo de Martín, de Orihuela, de 22 años, alto de cuerpo, lampiño, pelo castaño

En lo 27 de dicho mes sentaron plaza

104 Joan Martínez, hijo del mesmo, de Villanueva de los Infantes, de 18 años, mediana estatura, pelo castaño, poca barba.

105 Estanislao Sastre, hijo del mismo, de Priego, de 35 años, mediano de cuerpo, pelo castaño.

106 Vicente Vidal, hijo de Roque, de Xàtiva, de 18 años, delgado de cuerpo, pelo castaño.

107 José Martínez, hijo del mismo, de Muchamiel, de 21 años, mediana estatura, pelo castaño.

108 José Martínez, hijo de Bautista, de Muchamiel, de 18 años, mediana estatura, pelo castaño.

En 28 de dicho mes sentaron plaza

109 Pedro Pablo Gramaje, hijo de Pedro, de Bosoren (¿Borén?), de 32 años, rehecho de cuerpo, cerrado de barba, pelo negro.

110 Joan Torres, hijo de Vicente, de Alicante, de 16 años, mediana estatura, pelo rojo.

En 29 de dicho

111 Bartolomé Ribot, hijo de Pedro, de Mallorca, de 22 años, buena estatura, mellado y sobre la ceja derecha una señal de herida.

112 Miquel Bataller, hijo de Joan, de la Puebla del Duque, de 22 años, de buena estatura, pelo negro.

113 Tomás Fajor, hijo del mismo, del lugar de Salou, de 28 años, mediano de estatura, colorado de cara y pelos castaños.

114 Agustín Guarinos, hijo de Alejandro, de la huerta de Valencia, de 25 años, de mediana estatura, pelo castaño. 
En 30 de dicho mes

115 Jaime Zaragoza, de Monestro de Elche, de 18 años, buena estatura, cabello castaño y sin pelo de barba.

Primero de diciembre

116 Francisco Puente, hijo de Domingo, del lugar de Vioño, de 22 años, lampiño, pelo castaño, con dos cicatrices en la frente.

117 Diego Lana, hijo del mismo, de la ciudad de ¿Baluedro?, de 24 años, con una señal de herida sobre la nariz, pelo castaño.

118 Sebastián Avería, hijo de Gabriel, de ¿Aljoser?, de 35 años, buena estatura, barbirrojo, algo calvo.

En tres de dicho mes

119 Joan Hernández, hijo del mismo, de Galera, de 30 años, mediana estatura, con una señal encima de la ceja derecha, poca barba.

120 Joan Martín, hijo de Salvador, de ¿Moluedro?, de 20 años, buena estatura, poca barba, pelo castaño.

En 4 de dicho mes

121 Miguel Vallejos, hijo de Francisco, de la villa de Xixona, de 40 años, con una herida en la frente, calvo y mellado.

[121 bis] Ginés Juste, ${ }^{48}$ hijo de Lázaro, de la villa de la Raya de 22 años, pelo negro, buena estatura, poca barba.

122 Joan Ruiz, hijo del mismo, de la Alcantarilla, de 18 años, buena estatura, sin pelo en la barba, cabello negro.

En 6 de dicho mes

123 Marco Antonio Guillén, hijo de Jerónimo, de Ibi, de 18 años, buena estatura, pelo castaño y en el ojo derecho una verruga.

124 Josep Gozalbes, hijo de Joseph, de Muchamiel, de 18 años, mediana estatura, pelo rojo.

125 Roque Clavería, hijo de Gregorio, de Xàtiva, de 17 años, pelo castaño, tuerto.

126 Bernardo La Sala, hijo de Antonio, de ¿Alcavicer?, de 18 años, buena estatura, poca barba, pelo castaño.

En 7 de dicho mes

127 Gregorio Sis, hijo del mismo, de Valencia, de 13 años, pelo castaño y con señales de viruela en el rostro.

128 Fulgencio Ruiz, hijo de Joan, de Alhama, de 34 años, buena estatura, flaco de carnes, pelo castaño.

129 Pedro Roque, hijo de Joseph, de Xàtiva, de 16 años, mediana estatura, pelo castaño oscuro.

130 Joan Rodríguez, hijo de Antonio, de la ciudad de Santa Fe, de 25 años, cerrado de barba, pelo rojo.

131 Ginés Alcarás, hijo del mismo, de Sant Joan, buena estatura, sin pelo en la barba, pelo rojo.

132 Francisco Fenoll, hijo del mismo de Elche, de 22 años, buena estatura, pelo castaño, mellado.

48. Todo indica que el soldado Juste fue alistado, pero pasado por alto, habiendo, pues, 155 soldados alistados. 
133 Joan Linares, hijo de Joseph de Elche, de 40 años, rehecho de cuerpo, pelo castaño.

En 10 de dicho mes calvo.

134 Pedro Vidal, hijo de Pedro de Urbano, de Cartaya, de 30 años, de buena estatura,

135 Antonio Lledó, hijo de Urbano, de Sant Joan, de 20 años, pelo castaño, buena estatura.

136 Luis Babot, hijo de Jaime, de la villa de Relleu, de 18 años, de mediana estatura, pelo negro.

137 Antonio Julián, hijo del mismo, de la villa de ¿Almidiger?, de 14 años, mediana estatura, pelo rojo y picado de viruelas.

138 Bautista Zapata, hijo de Joseph, de Pego, de 23 años, buena estatura, con una cicatriz en la frente, pelo negro.

139 Miguel Moreno, hijo de Lorenzo, de Polope, de 18 años, mediano de cuerpo, pelo negro. barba.

140 Roque Claveria, hijo de Gregorio, de Xàtiva, de 16 años, tuerto y sin pelo en la

En 13 de dicho mes

141 Blas García, hijo de Pedro, de 31 años, buena estatura, de Orihuela, pelo negro, cerrado de barba.

142 Miquel Cerdà, hijo de Joseph, de Orihuela, de 15 años, sin pelo de barba, cabello negro.

143 Alejandro Tormo, hijo de Francisco, de Orihuela, de 17 años, sin pelo en la barba, con una cicatriz en la frente.

144 Alonso Ruiz, hijo de Jerónimo de Orihuela, de 20 años, mediana estatura, lampiño, con una herida en la barba.

145 Josep Silvestre, hijo de Bernardo, de Orihuela, de 24 años, poca barba, mediano cuerpo, pelo negro.

146 Diego Romero, hijo de Francisco, de Alicante, de 20 años, moreno de cara, pelo negro y poca barba.

147 Pedro de Soria, hijo de Álvaro, de Orihuela, de 30 años, mediana estatura con una cicatriz en la frente, pelo castaño.

148 Gregorio Rodríguez, hijo del mismo, de la Cantarilla (¿Alcantarilla?), buena estatura, pelo castaño largo.

149 Lorenzo Aparís, hijo de Jaime, de Valencia, de 22 años, buena estatura, poco bigote y sin pelo de barba.

150 Onofre Farinós, hijo del mismo, de Elche, de 18 años, mediana estatura y sin pelo de barba.

151 Joan Brotons, hijo de Tomás, de Elche, de 18 años, buena estatura, sin pelo en la barba, cabello castaño.

152 Domingo Vallejo, hijo de Francisco, de Elche, de 20 años, buena estatura, moreno de cara, lampiño.

153 Bartolomé Amorós, hijo de Tomás, de Caudete, de 30 años, buena estatura, pelo castaño oscuro.

154 Jaime Soler, de Murcia, hijo del mismo, de 30 años, pelo castaño, de mediano cuerpo $\gg,{ }^{49}$

49. AGS, GA, leg. 2.409, gobernador de Alicante al C.G., 20-XIl-1677. 
Todo indica que los cien hombres apalabrados fueron incrementados hasta los 155 finales -sin contar al propio Irles, el capellán, el sargento, los dos tambores y el paje, elevándose entonces su número hasta los 161- debido al tiempo de estancia extra en Alicante, pues a partir del 26 de noviembre y hasta el 13 de diciembre aún se incorporaron los 55 hombres finales. La partida, como se señaló antes, fue el día 21 de dicho mes.

A tenor de la edad de los hombres y de sus características físicas, no es de extrañar que se hubiese calificado dicha recluta como de buena calidad:

\section{GRÁFICO 1. EDADES DE LOS COMPONENTES DE LA COMPAÑÍA IRLES,} 1677

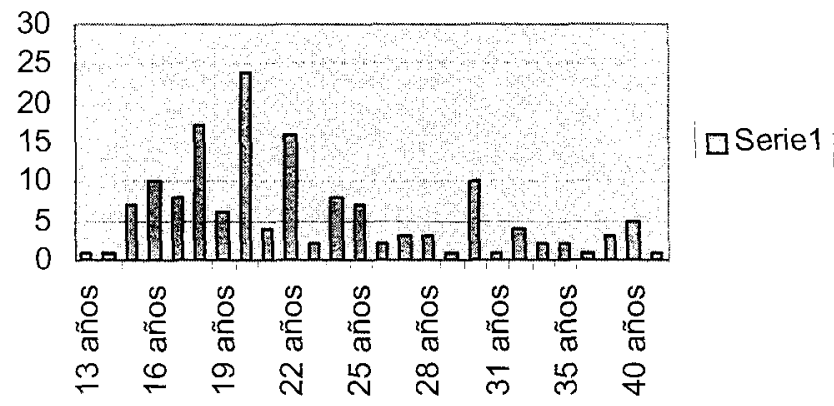

\section{GRÁFICO 2. EDAD DE LEVA, COMPAÑÍA IRLES (1677)}

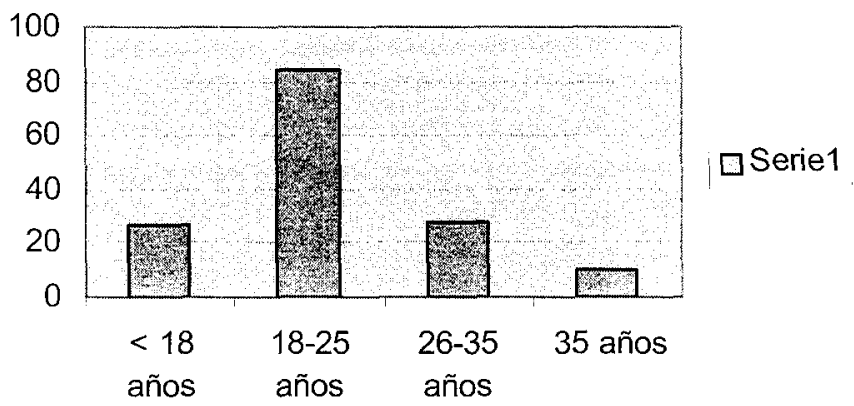

Fuente: AGS, GA, leg. 2.409, gobernador de Alicante al C.G., 20-XII1677. Elaboración propia.

Cien de estos hombres $(64,10 \%)$ tenían unas edades comprendidas entre los dieciséis y los veinticinco años, y sólo el $12 \%$ de sus integrantes tenían más de treinta años. Podemos comparar tales cifras con las de algunos tercios catalanes de esta época. En el caso del tercio de Barcelona para las campañas de 1667-1668, el 64,2\% de los hombres tenían menos de 25 años, y en el del año 1674 el 63,82\% eran, también, menores de 25 años. Disponemos, asimismo, de datos sobre tres compañías del tercio del Consell 
de cent de la ciudad de Barcelona en 1674: sobre 313 hombres, hasta $203(64,85 \%)$ tenían sus edades comprendidas entre los 18 y 25 años. Y en el caso de los tercios provinciales de Cataluña de 1695 y 1697 -tercios Copons y Darnius-, la amplia mayoría de hombres poseen entre 18 y 25 años; en el tercio de 1695, sólo de 18 a 20 años hay 283 levados, un $32,6 \%$ del total -que aumenta a un $74,88 \%$ si contemplamos el arco que va de los 18 a los 30 años. En el segundo ejemplo, el 69,3\% de los hombres tenía entre 18 y 30 años. En todos los casos vistos, el número de hombres de más de 35 años es inferior al $13 \%$ del total de levados. ${ }^{50}$

GRÁFICO 3. EDAD DE LEVA, TERCIO DE LA CIUDAD DE BARCELONA, 1674

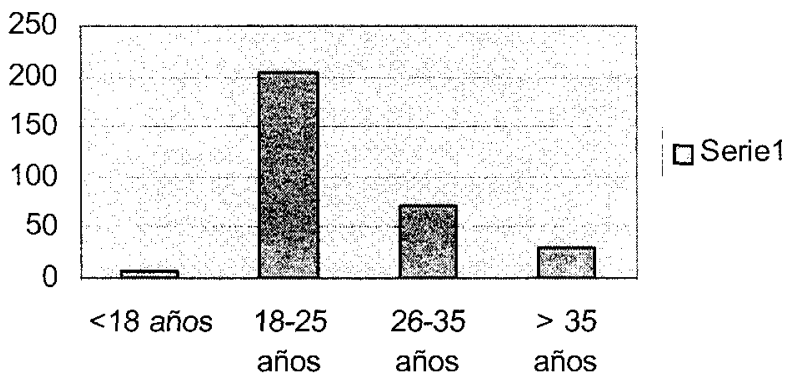

Fuente: Arxiu Històric de la Ciutat de Barcelona (AHCB), Consellers, C-XVI-13, tercio de la ciudad de Barcelona, 1674. Elaboración propia.

\section{GRÁFICO 4. EDAD DE LEVA, TERCIO COPONS, 1695}

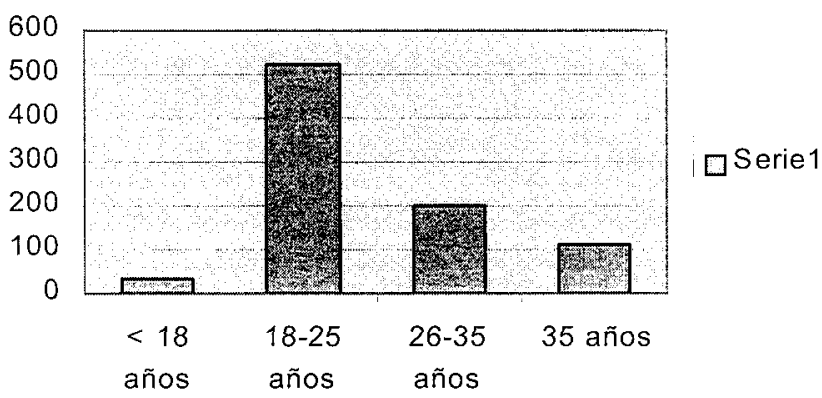

Fuente: A. Espino, Catalunya durante el reinado de Carlos II, Bellaterra, 1999, pp. 262-263. Elaboración propia.

50. A. Espino, Catalunya durante el reinado de Carlos II, Bellaterra, 1999, pp. 262-263. 


\section{GRÁFICO 5. EDAD DE LEVA, COMPAÑIIA DEL CAPITÁN CARDENYS (TERCIO DARNIUS), 1697}

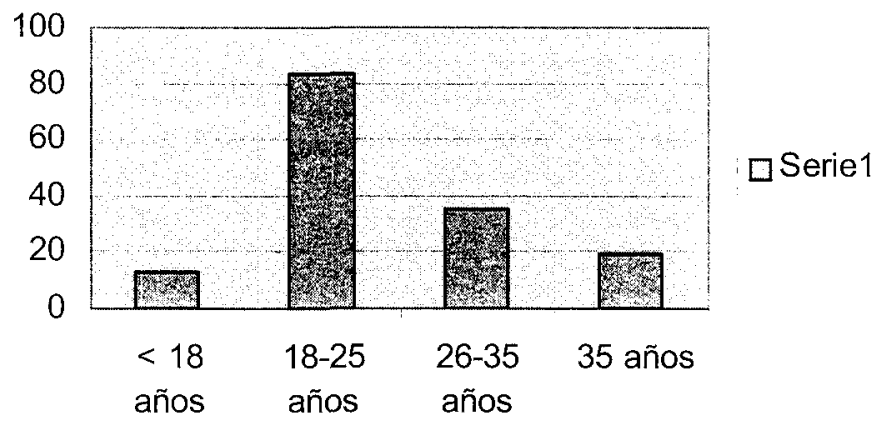

Fuente: A. Espino, Catalunya durante el reinado de Carlos II, Bellaterra, 1999, pp. 262-263. Elaboración propia.

Como se puede comprobar, los resultados de los gráficos $2,3,4$ y 5 son prácticamente idénticos y también coinciden con las edades de la banda de J. Berenguer (1680) estudiadas por H. Kamen. ${ }^{51}$

Por otro lado, hasta sesenta y nueve hombres de la compañía Irles fueron calificados como poseedores de una «buena estatura» y otros dos de cuerpos rehechos, es decir, fornidos, por uno sólo descrito como «flaco de carnes» y otro tuerto. Una situación bien distinta a la de algunas agrupaciones regnícolas como las pagadas por el Consell de Cent de la ciudad de Barcelona. Disponemos información sobre 146 casos de soldados considerados inútiles para el servicio en los tercios de la Ciudad Condal entre 1689 y 1697 . De dicha cifra, 32 (21,9\%) se declararon inútiles; sin especificar causa había 20 casos, seis eran mancos y otros seis deficientes mentales. Todos fueron descubiertos en plena campaña, lo que arroja mucha luz sobre la falta de seriedad a la hora de hacer la recluta, importando únicamente llenar los cupos asignados. Los casos más escandalosos son, posiblemente, los de personas de edad avanzada y con problemas en la vista, como ocurrió con el soldado F. Batet que «es troba cego (sic) de molts anys a esta part». Revisando otros casos particulares, los resultados son sorprendentes: M. Muñoz fue retirado «por ser simple y no poder-li encomanar un puesto»; P. Ribes y P. Coll se habían enrolado con sesenta y setenta años, respectivamente, no pudiendo seguir la marcha del tercio. J. Berfull fue rechazado por «no tenir forsas ni esperit per ser soldat»; J. Estevanell «per estar cansats de ensenyar-li lo que convé al servey del Rey y no és estat possible el poder-li enssenyar». M. Carol, por ejemplo, «és de ningún servey per estar continuament borratxo y no se li pot fiar cosa si no lo durmir». ${ }^{52}$

51. H. Kamen, La España de Carlos II, Barcelona, 1987², pp. 320-321.

52. A. Espino, Catalunya durante el reinado de Carlos II, Bellaterra, 1999, pp. 219-220. 
Todo, pues, indica la excelente calidad de los hombres aportados por G. Irles. En cuanto a su procedencia ninguna sorpresa. Una buena proporción de los hombres levados saldrán de localidades en el eje Alicante (trece alistados)-Elche (catorce alistados)Orihuela (nueve alistados)-Murcia (diez alistados); además de otras localidades en el entorno más cercano de las anteriores como Muchamiel (cinco alistados) y Sant Joan (cuatro alistados) en el caso de Alicante, o de Espinardo (dos alistados) y Alcantarilla (dos alistados) en el de Murcia. Asimismo, de localidades alicantinas como Xixona (tres alistados), Villena (dos alistados), Concentaina (dos alistados), Ibi (un alistado) o Alcoy (un alistado). Obviamente, Valencia debía estar representada (nueve alistados), pero también Játiva con diez u Onteniente con dos. Más al norte, Benicarló con tres alistados, y ya en Cataluña Salou con uno, igual que Lleida, Girona, Barcelona, Arenys de Mar o, incluso, Perpiñán. Tampoco era extraña la presencia de algunos albaceteños, granadinos y, también, algún sevillano entre las tropas reclutadas. 